\title{
Characteristics of Patients Having Splenic Involvement in Tuberculosis
}

\author{
Amal Chakroun ${ }^{1 *}$ (D), Makram Koubaa ${ }^{1}$ (D), Fatma Hammami ${ }^{1}$ (D), Wiem Feki ${ }^{2}$ (D), Khaoula Rekik ${ }^{1}$ (D),

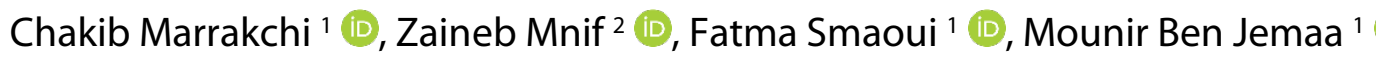 \\ ${ }^{1}$ Infectious Diseases Department, Extrapulmonary Research Unit UR17SP12, Hedi Chaker University Hospital, Sfax, Tunisia \\ ${ }^{2}$ Radiology Department, Hedi Chaker University Hospital, Sfax, Tunisia \\ * Corresponding author: Amal Chakroun E-mail: docamalchakroun@gmail.com ORCID: 0000-0001-9322-5222 \\ Received: 18 October 2020 Accepted: 20 December 2020
}

\begin{abstract}
Objective: One important, though poorly described, manifestation of Extra-pulmonary tuberculosis (EPTB) is that of splenic tuberculosis (TB). We aimed to identify the epidemiological, clinical and radiological characteristics of splenic TB in Southern Tunisia and to analyse its therapeutic and evolutionary modalities.
\end{abstract}

Materials and methods: TB-patients (pulmonary and/or extra-pulmonary) with abnormal splenic parenchymal lesion on radiologial exploration were scanned in the light of demographic, clinical, radiological features and response to treatment.

Results: We included 10 patients. Most of the patients (70\%) were aged more than 25 years and the sex ratio was 0.25 . Immunosupression was noted in 3 cases. Constitutional symptoms were common presentations apart from other abdominal symptoms. Most frequent ultrasound (US) findings were multiple focal hypoechoic lesions and splenomegaly. Computed tomography (CT) scan allowed a better characterization of the splenic lesions showing mainly micronodular spleen and hypodense nodudes. All patients received anti-TB drugs for a median of 13 months and splenectomy was not indicated in any case. The outcome was mostly favorable and death occurred in one case.

Conclusion: The splenic involvement in TB include both immunocompetant and immunosuppressed patients. It is mainly reported in disseminated form of the disease. Radiological findings are highly useful for the diagnosis but should always be correlated with overall clinical presentation with demonstration of tuberculosis at other body sites.

Keywords: Immunosupression, spleen, tuberculosis, computed tomography, antitubercular

\section{INTRODUCTION}

Tuberculosis (TB) continues to be a major health problem despite recent advances in its diagnosis and management. There are diverse manifestations of this disease with increasing trend of presentation as EPTB especially in the era of HIV infection. Among the EPTB, splenic TB is rare and poorly described in the available literature [1]. Tuberculous involvement of spleen is exceptionally reported in immunocompetent host and usually seen in disseminated or miliary form of the disease and in patients infected with HIV [2]. Various pathological forms of splenic involvement are described. Miliary tuberculosis, nodular tuberculosis, tuberculous spleen abscess, calcific tuberculosis, and mixed type tuberculosis are few among them [3]. Numerous single 
Table 1. Demographic and Clinical characteristics of patients having splenic tuberculosis $(n=10)$

\begin{tabular}{|c|c|c|c|}
\hline \multicolumn{2}{|c|}{ Characteristics } & Number & Percentage (\%) \\
\hline \multirow{2}{*}{ Age } & $<25$ years-old & 3 & 30 \\
\cline { 2 - 4 } & $>$ 25years-old & 7 & 70 \\
\hline \multirow{2}{*}{ Sex } & Male & 2 & 20 \\
\cline { 2 - 4 } & Female & 8 & 10 \\
\hline \multirow{3}{*}{ Immunosuppression } & HIV infection & 1 & 20 \\
\cline { 2 - 4 } & Long-term corticosteroid therapy & 2 & 80 \\
\cline { 2 - 4 } & Fever & 8 & 80 \\
\cline { 2 - 4 } & Anorexia & 8 & 70 \\
\cline { 2 - 4 } & Weight loss & 7 & 60 \\
\hline \multirow{2}{*}{ Abdominal symptoms } & Night sweats & 6 & 30 \\
\cline { 2 - 4 } & Pain & 3 & 10 \\
\hline
\end{tabular}

HIV: Human Immunodeficiency Virus

Table 2. Number and list of tubercular sites other than spleen

\begin{tabular}{|c|c|c|c|}
\hline \multicolumn{2}{|c|}{ Characteristics } & Number & Percentage (\%) \\
\hline \multirow{3}{*}{\begin{tabular}{c} 
Number of sites involved \\
\cline { 2 - 4 }
\end{tabular}} & Two sites & 3 & 30 \\
\cline { 2 - 4 } & Three sites & 3 & 30 \\
\hline \multirow{4}{*}{$\begin{array}{c}\text { Anatomical involved } \\
\text { sites }\end{array}$} & More than three sites & 4 & 40 \\
\cline { 2 - 4 } & Lungs & 6 & 60 \\
\cline { 2 - 4 } & Lymphnode & 8 & 10 \\
\cline { 2 - 4 } & Brain & 1 & 20 \\
\cline { 2 - 4 } & Peritoneal & 2 & 40 \\
\cline { 2 - 4 } & Hepatic & 4 & 30 \\
\hline
\end{tabular}

HIV: Human Immunodeficiency Virus

case reports have been described, but there have been no attempts to catalogue the varied dermographic, clinical and radiographic characteristics of splenic TB. Our serie analyzes clinicoradiological manifestations of this form of disease in Southern Tunisia.

\section{MATERIALS AND METHODS}

This study retrospectively analyzes clinical record of patients having splenic involvement in TB attending our departement during the last twenty-seven years (19922019) Socio-demographic characteristics including age and gender were reviewed. Clinical and evolutionary features, such as diagnostic methods, clinical presentation, treatment, the follow up duration and the disease outcome.

The diagnosis of tuberculosis was established by demonstration of Mycobacterium tuberculosis on smear and/or culture in clinical specimens or histological demonstration of caseating granulomas/ acid-fast bacilli in tissue specimens or with highly suggestive clinicoradiological features of tuberculosis with response to antituberculosis drugs.

\section{RESULTS}

During a 27-year study period, we included 470 new cases of EPTB among whom 10 patients had splenic involevement representing $2.1 \%$. Demographic and clinical characteristics of these patients are summarized in Table 1. There were 8 females and 2 males with a sex ratio of 0.25 . The median age was 36 years (range 15-63 years). Immunosupression was reported in $30 \%$ of cases: One patient was co-infected with HIV and two patients were recieiving long-term corticosteroid therapy. Clinical findings were dominated by constitutional symptoms such as fever (80\%), weight loss (70\%) and night sweats (60\%). Abdominal pain was noted in 3 cases. Physical examination showed splenomegaly in $40 \%$ cases and abdominal effusion in $20 \%$ cases. The most common hematological abnormalities was inflammatory anemia (80\%) and lymphopenia (60\%). All patients had simultaneously others sites of TB (Table 2 ). The main sites were lymph nodes in 8 cases (80\%), followed by lungs in 6 cases $(60 \%)$, and liver in 4 cases $(40 \%)$. TB- diagnosis was established by demonstration of Mycobacterium tuberculosis in clinical specimens in 4 cases, histological demonstration 
Table 3. Radiological findings in splenic tuberculosis

\begin{tabular}{|c|c|c|c|}
\hline Imaging & Findings & Number & Percentage (\%) \\
\hline \multirow{3}{*}{ Ultrasound $(\mathrm{n}=5)$} & Multiple focal hypoechoic lesions & 3 & 30 \\
\cline { 2 - 4 } & Splenomegaly & 3 & 30 \\
\cline { 2 - 4 } & Splenic abscess & 4 & 40 \\
\hline \multirow{2}{*}{$\begin{array}{c}\text { Computed Tomography } \\
\text { Scan ( } \mathrm{n}=10)\end{array}$} & Micronodular spleen & 6 & 60 \\
\cline { 2 - 4 } & Multiple hypodense nodules & 8 & 80 \\
\cline { 2 - 4 } & Splenomegaly with splenic abscesses & 1 & 10 \\
\hline
\end{tabular}

HIV: Human Immunodeficiency Virus

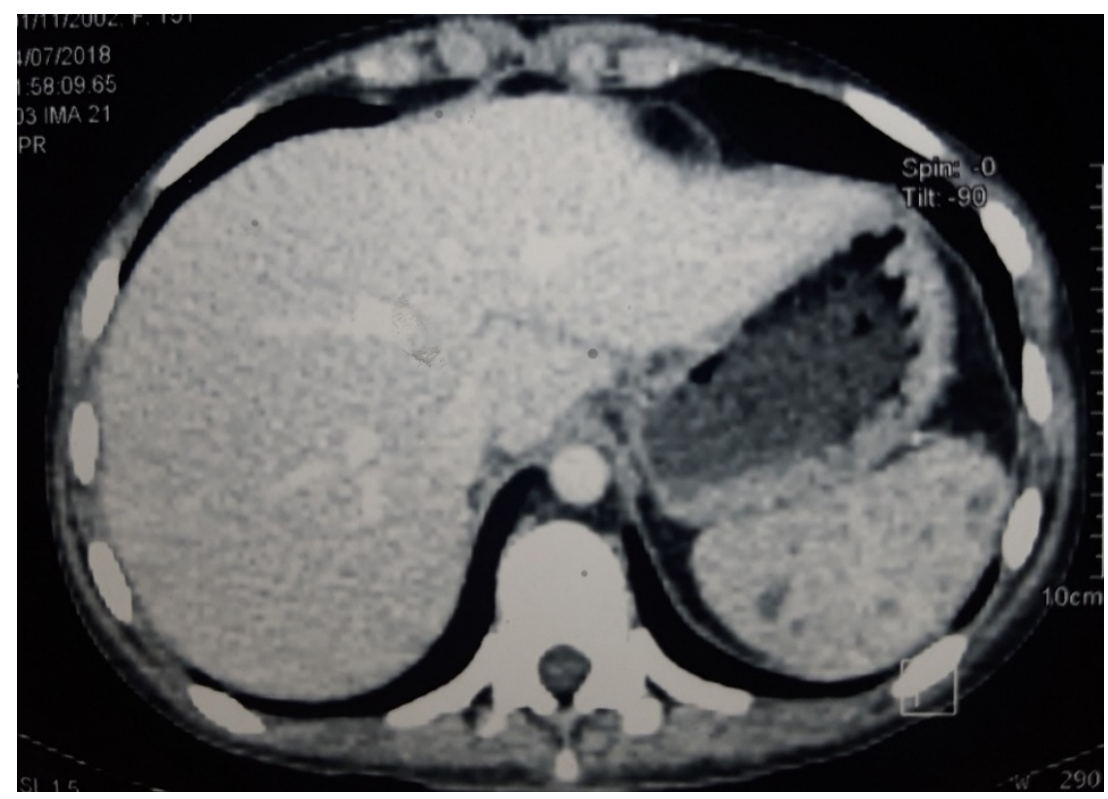

Figure 1. Axial cut of computed tomography showing micronodular normal sized spleen

in tissue specimens in 6 cases (60\%) and with highly suggestive clinico-radiological features of tuberculosis with response to anti-tuberculosis drugs in 2 cases (20\%). Ultrasound of the spleen was realised in 5 cases showing multiple focal hypoechoic lesions in 2 cases (40\%), isolated splenomegaly in 2 cases (40\%) and splenic abscess in 1 case (10\%). CT scan showed micronodular spleen in 5 cases (50\%), multiple hypodense nodules in 3 cases (30\%), and splenomegaly with multiple fluid density formations (splenic abscesses) in 2 cases (20\%) (Table 3). All patients received quadruple anti-TB drugs for two months then switched with bitherapy. The median duration of treatment was 13 months [6-24]. Sides effects were noted in 3 cases (30\%): Hepatic cytolysis in 2 cases and rash skin in 1 case. Splenectomy was not indicated in any case. The outcome was favorable in 9 cases (90\%) and we noted one death (10\%).

\section{DISCUSSION}

Out of various EPTB entities, the splenic TB is rare. Splenic involvement is much more common in patients with disseminated TB for whom the diagnosis has been made from other sites [4]. However, there are reports of isolated splenic involvement too [1]. Splenic TB, as for other extrapulmonary forms of TB should always be included in differential diagnosis of patients presenting with pyrexia of unknown origin [5]. Delay in diagnosis is frequent. Few of the reasons for this delay being non specific clinical presentation, difficulties in confirming the diagnosis and prevalent concepts requiring the surgical intervention for confirmation of the disease and its subsequent treatment. Clinically, there are no characteristic features and constitutional symptoms dominate [6]. The most common form of detection is via a palpable spleen by routine physical examination. The diagnostic workup for patients with suspected TB and splenomegaly on physical examination is broad and complicated by the co-occurrence of multiple other conditions seen in these patients in developing countries [4].

Splenic TB is traditionally been thought as a cause of small splenomegaly, however massive enlargement has also been reported [3]. Very rarely, splenic involvement is totally asymptomatic [1]. Haematological changes are those seen in TB in general. Most patients demonstrate normochromic or hypochromic-normocytic anaemia of chronic disease [7]. 
Radiologically, splenic TB presents in miliary form or macronodular form [8]. Miliary form is characterized by multiple small nodules that sometimes may not be discernable. They are better delineated on high resolution ultrasound as ill-defined hypoechoic lesions [9]. This form can also lead to splenomegaly only [6]. The macronodular form presents as single or multiple larger nodule/s or mass/es that are hypodense on computed tomography (CT) and hypoechoic on ultrasound. These nodules commonly have an appearance similar to abscesses showing peripheral enhancement on CT and anechoic areas or debris on ultrasound $[9,10]$. However, a single large nodule may mimic a neoplasm [6,9]. Backer et al. described the features of splenic TB on magnetic resonance imaging. Peripheral contrast enhancement with centrally nonenhancing area is one of the typical manifestations in this study [10]. However, largely, the findings are nonspecific and image-guided fineneedle aspiration and cytology play an important role to confirm diagnosis [6]. Treatement is mainly medical based on antitubercular drugs. The optimal duration of treatment for splenic TB is currently unknown [11]. As most patients with splenic TB have disseminated disease, a 12- month course of anti-tuberculous treatment appears to be appropriate [11,12]. Prognosis is good with medical treatment alone, even in patients infected with HIV $[11,13,14]$. Curative splenectomy does not appear to be essential $[11,13]$. It should be discussed in the event of resistance in Koch's bacillus or worsening under medical treatment, with an attitude that is all the more conservative as the patient is young [14]. Some teams associate radioguided drainage when it involves fluid images larger than 5 $\mathrm{cm}$ in diameter, with very satisfying results [14].

\section{CONCLUSION}

High degree of suspicion should be attributed to splenic involvement in TB cases, because there are no specific symptoms that can characterize splenic TB. However, presence of pulomonary TB or EPTB with fever, abdominal pain and abnormal splenic parenchymal lesion is a strong indication of splenic involvement in both immunocompetant and immunocompromised patients. The clinical and radiological response to TB treatment should be closely monitored to ensure a good outcome.

Author contributions: All authors were involved in concept, design, collection of data, interpretation, writing, and critically revising the article. All authors approve final version of the article.

Funding: The authors received no financial support for the research and/or authorship of this article.

Declaration of interest: There is no conflict of interest.

Data availability: Data generated or analysed during this study are available from the authors on request.

\section{REFERENCES}

1. Dixit R, Arya MK, Panjabi M, Gupta A, Paramez AR. Clinical profile of patients having splenic involvement in tuberculosis. Indian J Tuberc. 2010;57(1):25-30. PMID: 20420041.

2. Masoodi I. Splenic tuberculosis: Report of two cases and literature review. BJMP 2017;10(1):a1001.

3. Gupta A. Splenic tuberculosis: A comprehensive review of literature. Polski Przeglad Chirurgiczny/ Polish Journal of Surgery. 2018; 90: 49-51. (doi: 10.5604/01.3001.0012.1754).

4. Sharma SK, Smith-Rohrberg D, Tahir M, Mohan A, Seith A. Radiological manifestations of splenic tuberculosis: a 23patient case series from India. Indian J Med Res. 2007; 125(5): 669-78. PMID: 17642503.

5. Ozaras R, Celik AD, Zengin K, Mert A, OzturkK R, Cicek Y, et al. Is laparotomy necessary in the diagnosis of fever of unknown origin? Acta hir Belg. 2005; 105(1): 89-92. (doi: 10.1080/00015458.2005.11679673).

6. Gupta P, Dhaka N, Rohilla M. Isolated splenic tuberculosis presenting as an unusual splenic mass. Int J Mycobacteriol. 2018; 7(4): 397-8. (doi: 10.4103/ijmy.ijmy_120_18).

7. Singh B, Ramdial PK, Royeppen E, Moodley J, Chetty R. Isolated splenic tuberculosis. Trop Doct. 2005; 35(1): 489. (doi: 10.1258/0049475053001976).

8. Lee WS, Choi ST, Kim KK. Splenic abscess: A single institution study and review of the literature.Yonsei Medical Journal. Yonsei University College of Medicine; 2011; 52: 288-92. (doi: 10.3349/ymj.2011.52.2.288).

9. Gupta P, Kumar S, Sharma V, Mandavdhare H, Dhaka N, Sinha SK, et al. Common and uncommon imaging features of abdominal tuberculosis. Journal of Medical Imaging and Radiation Oncology. Blackwell Publishing; 2019; 63: 329-39. (doi: 10.1111/1754-9485.12874).

10. De Backer Al, Vanhoenacker FM, Mortelé KJ, Vanschoubroeck IJ, De Keulenaer BL, Parizel PM. MRI features of focal splenic lesions in patients with disseminated tuberculosis. Am J Roentgenol. 2006; 186(4): 1097-102. (doi: 10.2214/AJR.05.0032).

11. Ho PL, Chim CS, Yuen KY. Isolated splenic tuberculosis presenting with pyrexia of unknown origin. Scand J Infect Dis. 2000; 32(6): 700-1. (doi: 10.1080/003655400459685). 
12. Bass JB Jr, Farer LS, Hopewell PC, O'Brien R, Jacobs RF, Ruben F, Snider DE Jr, Thornton G. Treatment of tuberculosis and tuberculosis infection in adults and children. Am J Respir Crit Care Med. 1994; 149(5): 135974. Available at: https://www.jstor.org/stable/4458711
13. González-López A, Dronda F, Alonso-Sanz M, Chaves F, Fernández-Martin I, López-Cubero L. Clinical significance of splenic tuberculosis in patients infected with human immunodeficiency virus. Clin Infect Dis. 1997; 24(6): 1248-51. (doi: 10.1086/513629).

14. Jira M, Sekkach Y, Abouzahir A, Amezyane T, Ghafir D. Tuberculose hépato-splénique. Press Medicale. 2015; 44(2): 258-9. (doi: 10.1016/j.Ipm.2014.04.022). 